\title{
What a long, strange trip it's been. . .
}

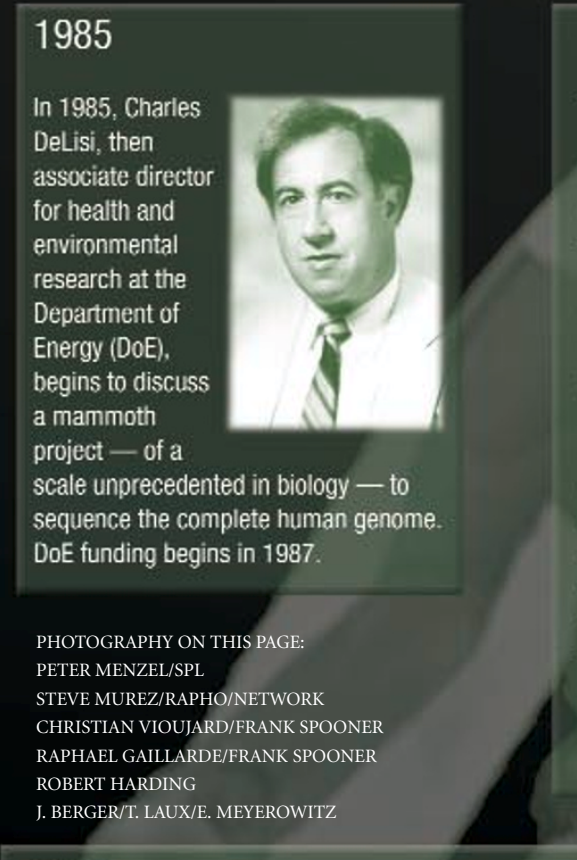

1998

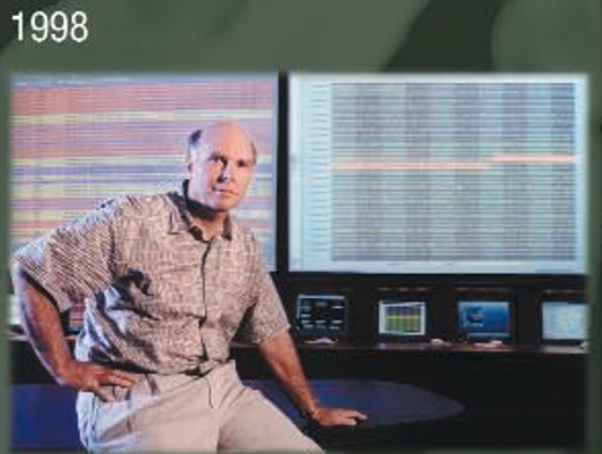

In May 1998, Venter forms a company to sequence the human genome within three years. The company, later named Celera, will use an ambitious 'whole genome shotgun' method, which involves assembling the genome without using maps. But its data release policy will not follow the Bermuda principles.
1988

The National Institutes of Health (NIH) establishes the Office of Human

Genome

Research in

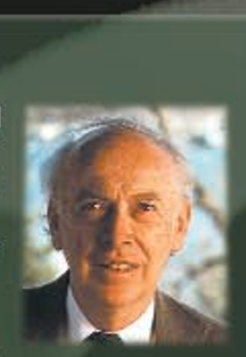

September 1988. Renamed the National Center for Human Genome Research (NCHGR) a year later, its director is James Watson, co-discoverer of the double helix structure of DNA. Watson's testimony to the US Congress, in which he pledged to devote a small fraction of the project's budget to 'ethical, legal and social' issues, had proved instrumental in garnering political support.
Early 1990 s

With sequencing still slow and expensive, the genome project adopts a 'map-first, sequence-later' strategy. In the early 1990s, two Parisian laboratories, the Centre d'Etude du Polymorphisme Humain and Généthon, have an integral role in mapping - underlining the project's international character. The labs' driving forces are Daniel Cohen (top) and Jean Weissenbach. Later, the genome project constructs a higher-resolution map that is used to sequence and assemble

the human genome.

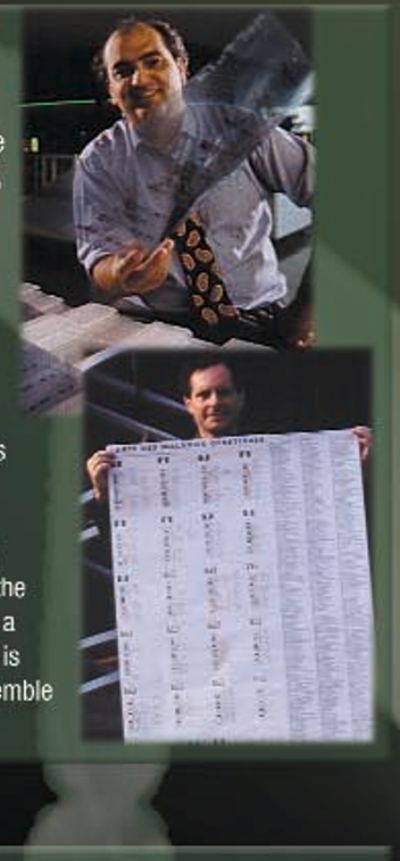

1999

The public project responds to Venter's challenge. By early 1999 , it is on track to produce a draft genome sequence by 2000 . Increasingly, the bulk of the sequencing takes place in five huge centres: at the Whitehead Institute for Biomedical Research in Cambridge, Massachusetts; the Sanger Centre near Cambridge, UK; Baylor College of Medicine in Houston; Washington University in St Louis; and the DoE's Joint Genome Institute (JGI) in Walnut Creek, California. The centres' leaders are dubbed the 'G5'. Here, Robert Waterston of Washington University in St Louis and John Sulston of the Sanger Centre are pictured in a rare moment of relaxation, while Trevor Hawkins and Elbert Branscomb of the JGI prepare samples.
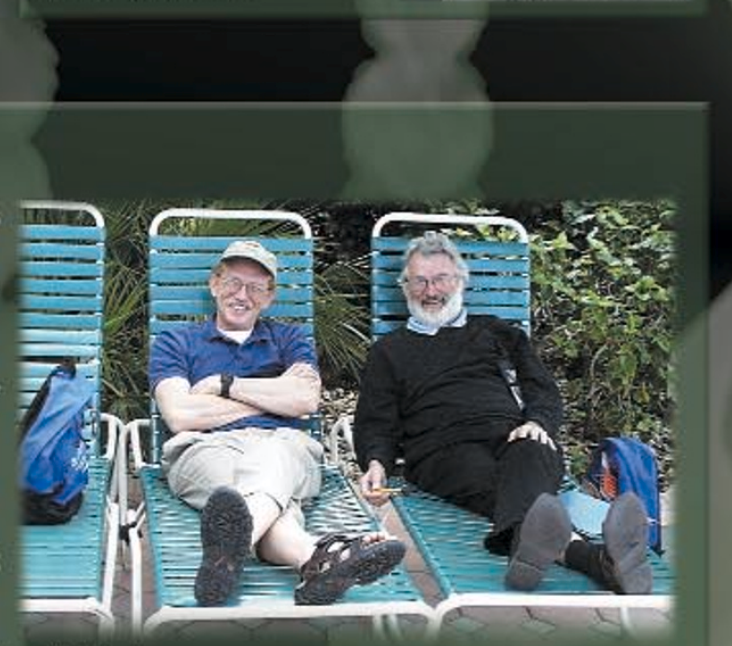

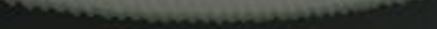

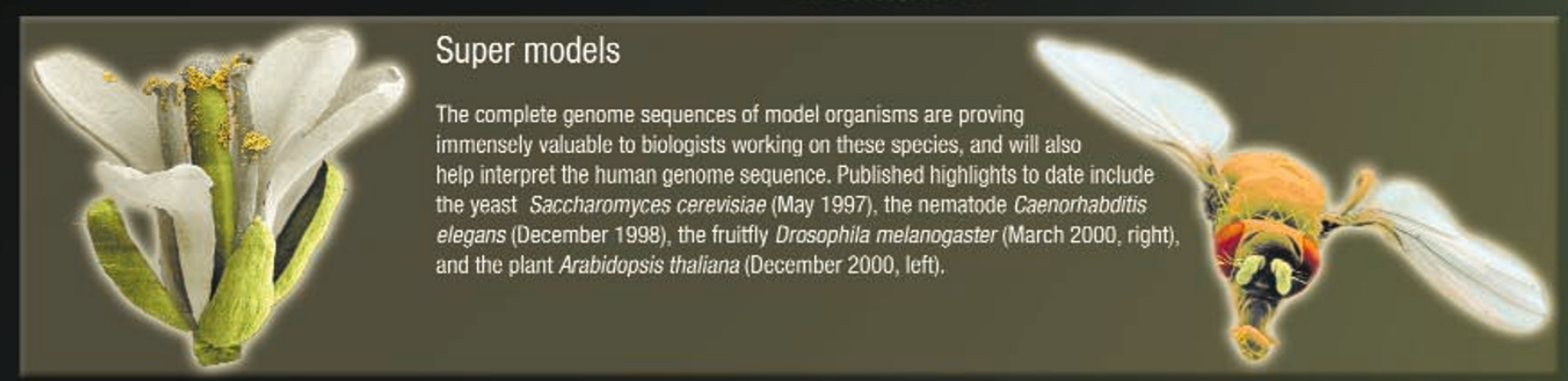


The draft human genome sequence published in Nature this week is the culmination of 15 years of work, involving 20 sequencing centres in six countries. Here, we present a reminder of some of the key moments.

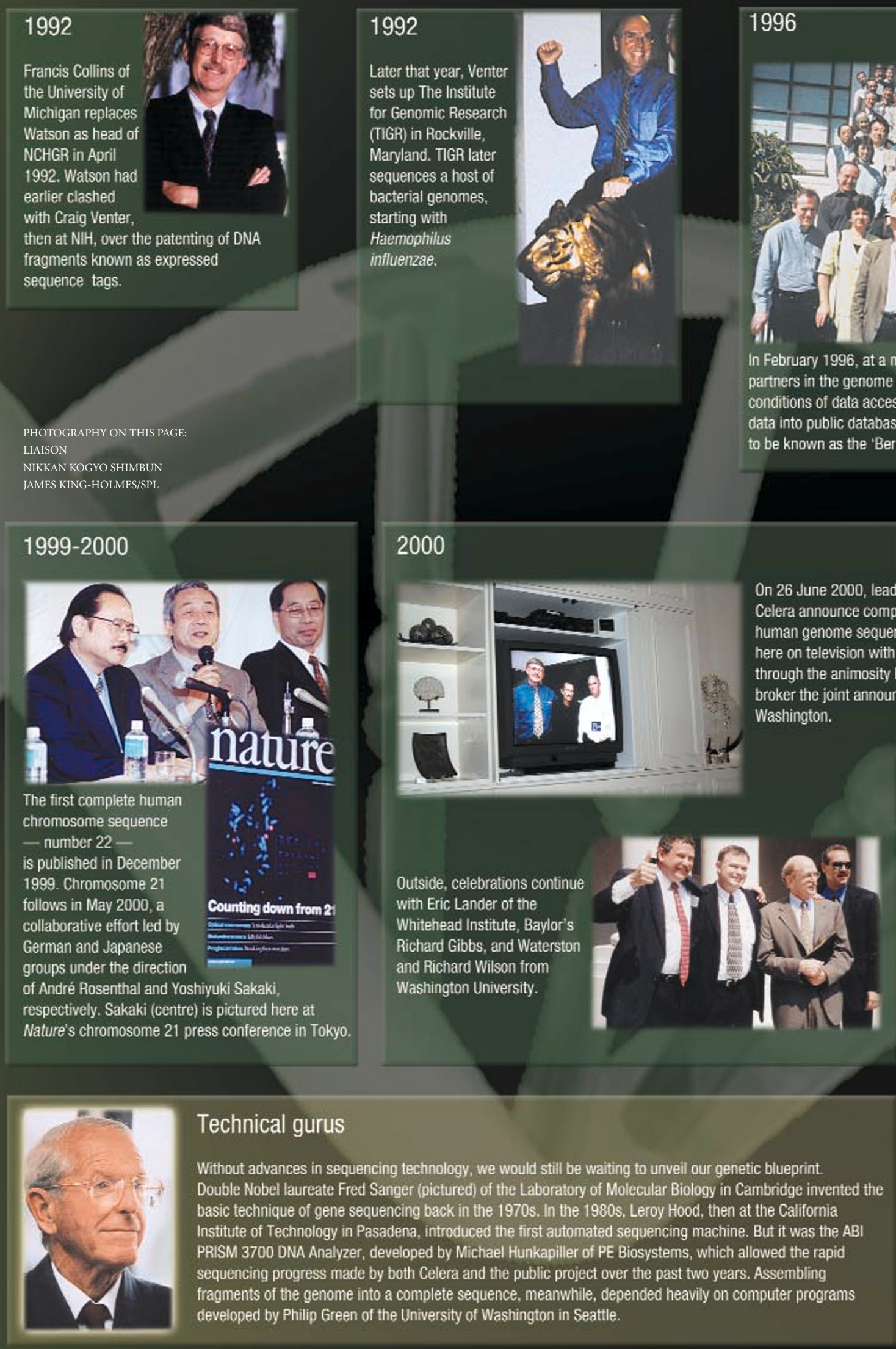

This week

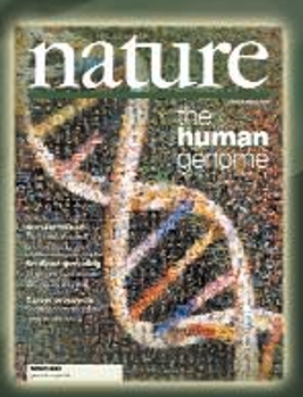

Finally, this week sees the publication of the draft genome, the public sequence in Nature, Celera's in Science.

We are grateful for contributions and input from Francis Collins, Richard Gibbs, Victor McKusick, John McPherson, David Stewart and the staff of the Cold Spring Harbor Laboratory. 